\title{
BCR-ABL and CDKN2A: a dropped connection
}

\section{Richard T. Williams* and Charles J. Sherr ${ }^{\ddagger}$}

In their recent Review of chronic myeloid leukamia (CML) stem cell biology (Savona, M. \& Talpaz, M. Getting to the stem of chronic myeloid leukemia. Nature Rev. Cancer 8, 341350) ${ }^{1}$, Savona and Talpaz focus their attention exclusively on deregulated self-renewal mechanisms in Philadelphia chromosome $(\mathrm{Ph})^{+}$ hematopoietic stem cells (HSCs) in chronicphase CML and on the role of $\beta$-catenin abnormalities in granulocyte-macrophage progenitors in myeloid blast crisis. However, a review of genomic abnormalities in lymphoid blast crisis provides insights into alternative mechanisms of progenitor self-renewal in BCR-ABL-driven diseases. Deletion of the CDKN2A locus (encoding the INK4A and ARF tumour suppressor genes) frequently occurs in the progression of CML from chronic-phase to lymphoid, but not myeloid, blast crisis ${ }^{2}$, and a recent genome-wide analysis ${ }^{3}$ (published concurrently with this CML review) has reinforced the conclusions of earlier studies. INK4A and $A R F$ share common second and third exons, are translated in alternate reading frames, and exhibit no sequence similarity ${ }^{4}$. Whereas p $16^{\text {INK4A }}$ is a bona fide cyclin-dependent kinase inhibitor, p14 ${ }^{\text {ARF }}$ ( $\mathrm{p} 19^{\text {Arf }}$ in mice) is not, but instead regulates p53 tumour suppressor function through its interaction with MDM2 (REF. 5). BCR-ABL induces p19 $9^{\text {Arf }}$ in vivo to oppose tumour development, but the combination of $\mathrm{BCR}-\mathrm{ABL}$ expression and Arf inactivation is sufficient to generate leukaemia-initiating cells in a murine model of $\mathrm{Ph}^{+}$acute lymphocytic leukaemia ${ }^{6}$. Therefore, in BCR-ABL-driven lymphoid leukaemias - specifically, CML lymphoid blast crisis and $\mathrm{Ph}^{+}$acute lymphocytic leukaemia - deletion of INK4A and ARF in committed $\mathrm{Ph}^{+}$ lymphoid blasts is expected to simultaneously disrupt both the RB and p53 tumour suppressor networks, thereby facilitating leukaemiainitiating cell self-renewal and enhancing targeted therapeutic resistance in vivo.

* Departments of Oncology and of Genetics \& Tumor Cell Biology and ${ }^{\ddagger}$ Howard Hughes Medical Institute, St. Jude Children's Research Hospital, 262 Danny Thomas Place, Memphis, Tennessee 38105, USA. Correspondence to R.T.W. e-mail: richard.williams@stjude.org

1. Savona, M. \& Talpaz, M. Getting to the stem of chronic myeloid leukemia. Nature Rev. Cancer 8 341-350 (2008).

2. Calabretta, B. $\&$ Perrotti, D. The biology of CML blast crisis. Blood 103, 4010-4022 (2004).

3. Mullighan, C. G. et al. $B C R-A B L 1$ lymphoblastic leukaemia is characterized by the deletion of Ikaros. Nature, 453, 110-114 (2008).

4. Quelle, D. E. et al. Alternative reading frames of the INK4a tumor suppressor gene encode two unrelated proteins capable of inducing cell cycle arrest. Cell 83, 993-1000 (1995).

5. Sherr, C. J. \& McCormick, F. The RB and p53 pathways in cancer. Cancer Cell 2, 103-112 (2002).

6. Williams, R. T., den Besten, W. \& Sherr, C. J. Cytokinedependent imatinib resistance in mouse $\mathrm{BCR}-\mathrm{ABL}^{+}$, Arf-null lymphoblastic leukemia. Genes Dev. 21, 2283-2287 (2007) 